\title{
A one-step, modular route to optically-active diphos ligands $\dagger$
}

Cite this: Chem. Commun., 2015, 51, 10206

Received 27th April 2015,

Accepted 15th May 2015

DOI: $10.1039 / c 5 c c 03517 a$

www.rsc.org/chemcomm

\author{
E. Louise Hazeland, Andy M. Chapman, Paul G. Pringle* and Hazel A. Sparkes
}

A chlorosilane elimination reaction has been developed that allows the efficient synthesis of optically pure $C_{1}$-symmetric, $C_{1}$-backboned diphosphines with a wide variety of stereoelectronic characteristics.

Asymmetric hydrogenation, catalyzed by metal complexes of optically active phosphines, was a landmark discovery in chemistry. ${ }^{1,2}$ Numerous diphosphines ${ }^{3-9}$ have been invented for the enantioselective hydrogenation of alkenes, ketones and imines and several have found industrial applications. ${ }^{10,11}$ The diphos ligands A-F shown in Fig. 1 represent milestones en route to the current understanding of the features that create an effective ligand for asymmetric catalysis and they continue to inspire the design of new ligands. ${ }^{12}$

The high enantioselectivity obtained with catalysts based on $C_{2}$ - or $C_{1}$-symmetric diphosphines has been rationalized in terms of the degree of control of the metal binding site offered by the chelates involved. ${ }^{13}$ For example the rigid 4-membered rings formed by the $\mathrm{C}_{1}$-backboned $\mathbf{E}$ and $\mathbf{F}$ (Fig. 1) have been

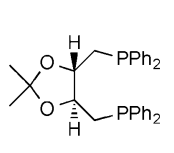

A

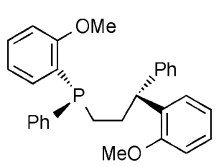

B

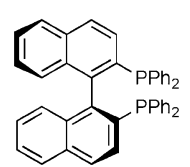

c

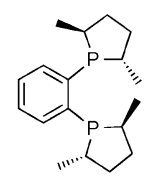

D<smiles>CC(C)(C)[Pb](C)(CP(C)(C)(C)C)C(C)(C)C</smiles>

E

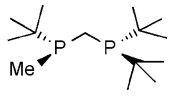

$\mathbf{F}$

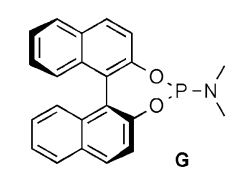

Fig. 1 Phosphorus ligands for asymmetric hydrogenation. $\mathbf{A}=\operatorname{diop}^{3}$ $\mathbf{B}=$ dipamp; $^{4} \mathbf{C}=$ binap; $^{5} \mathbf{D}=$ DuPhos; $^{6} \mathbf{E}=$ miniphos; $^{7} \mathbf{F}=$ trichickenfootphos; $^{8} \mathrm{G}=$ monophos. $^{9}$

School of Chemistry, University of Bristol, Cantock's Close, Bristol, BS8 1TS, UK. E-mail: paul.pringle@bristol.ac.uk

$\dagger$ Electronic supplementary information (ESI) available: Experimental details, additional spectra and crystallographic data. CCDC 1059329 and 1059330. For ESI and crystallographic data in CIF or other electronic format see DOI: 10.1039/ c5cc03517a spectacularly effective for asymmetric hydrogenation, ${ }^{7,8,14}$ and it is the rigidity of the metal chelates that appears to be a critical feature of these catalysts. Despite the multitude of diphos ligands that have been prepared, there continues to be a need for new ones because, as several authors have noted, ligand discovery remains largely an empirical rather than a rational endeavour. ${ }^{15} \mathrm{~A}$ disadvantage of diphos ligands is that their synthesis is often multistep and/or requires an optical resolution step, making systematic refinement of their structures time-consuming and laborious. ${ }^{16} \mathrm{~A}$ major reason why monophos ligands such as $\mathbf{G}$ have attracted attention ${ }^{17}$ is that their synthesis is simple, modular and so reliable that they have been employed in high-throughput experimentation (HTE). Here we report a simple, one-step route to $\mathrm{C}_{1}$-linked diphos ligands that has the capacity to create a library of optically-active diphos ligands rapidly.

The construction of achiral $\mathrm{C}_{1}$-linked diphosphines by an Si-P exchange reaction such as that shown in eqn (1) has been previously reported. ${ }^{18,19}$ The attraction of this route is that the volatile by-product is readily removed and therefore we have investigated its potential as the basis for a general route to optically active, $\mathrm{C}_{1}$-linked diphos ligands.

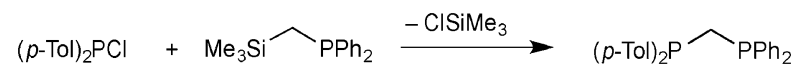

The reaction of chlorophosphite 1a with the trimethylsilylmethyl-phosphine 2a gave the diphos ligand $\mathbf{L}_{\mathbf{a}}$ quantitatively (eqn (2)).

$$
\overbrace{1 \mathrm{O}}^{\mathrm{O}} \mathrm{P}-\mathrm{Cl}+\mathrm{Me}_{3} \mathrm{Si} \sim \mathrm{PPh}_{2} \stackrel{-\mathrm{ClSiMe}_{3}}{\longrightarrow}
$$

The reactants in eqn (2) are readily varied and easily prepared. ${ }^{19-22}$ Thus $\mathbf{L}_{\mathbf{b}-\mathbf{f}}$ are produced in high yields from the reactions of trimethylsilylmethylphosphines $\mathbf{2 b - \mathbf { d }}$ with the 


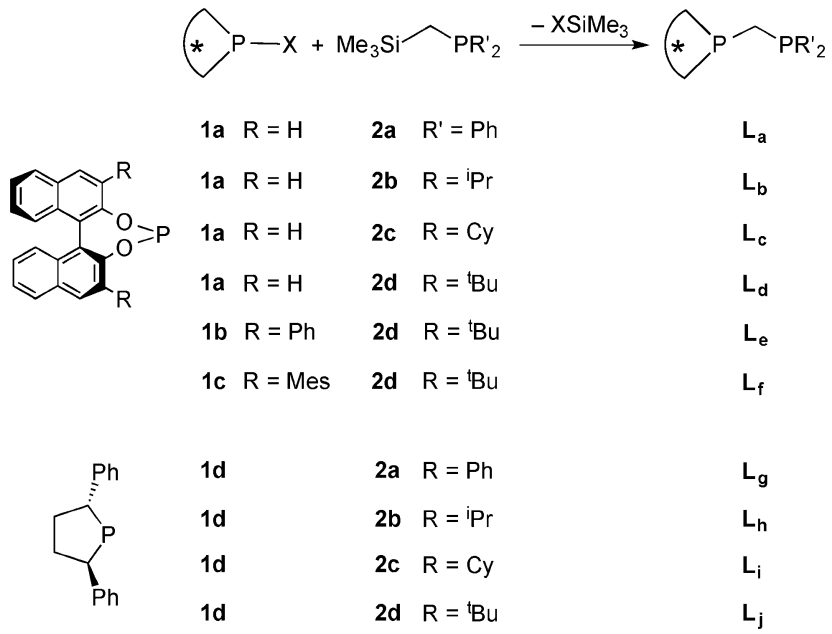

Scheme 1 Synthesis of the diphos ligands $\mathrm{L}_{\mathrm{a}-\mathrm{j}}$. $\mathrm{X}=\mathrm{Cl}$ in all cases except for $\mathbf{1 b}$ and $\mathbf{1 c}$ where $\mathrm{X}=\mathrm{Br}$.

corresponding optically-pure halophosphites 1a-c (Scheme 1). A significant extension of this process was achieved by employing the optically pure chlorophosphacycle $\mathbf{1 d}$ (Scheme 1) to produce $\mathbf{L}_{\mathbf{g}-\mathbf{j}}$. The crude products $\mathbf{L}_{\mathbf{a}-\mathbf{j}}$ were sufficiently pure to be used in catalysis without further purification.

The complexes [Rh(diene)L] (3) where diene $=1,5$-cyclooctadiene or norbornadiene were generated by the addition of $\mathbf{L}_{\mathbf{a}-\mathbf{j}}$ to $\left.[\mathrm{Rh} \text { (diene) })_{2}\right]\left[\mathrm{BF}_{4}\right]$ in $\mathrm{CH}_{2} \mathrm{Cl}_{2}$ and in each case the product was identified from the characteristic AMX pattern in its ${ }^{31} \mathrm{P}$ NMR spectrum (see ESI $\dagger$ for details). Representative examples of 3, where $\mathbf{L}=\mathbf{L}_{\mathbf{d}}$ or $\mathbf{L}_{\mathbf{g}-\mathbf{j}}$, have been isolated and fully characterised. The ligands were screened for the asymmetric hydrogenation of the three benchmark substrates DMI, MAA and MAC (structures shown below) and the results are given in Table 1 and depicted graphically in Fig. 2 from which it is clear that significant variation in selectivity occurs for ostensibly small changes in ligand structure.<smiles>C=C(CC(C)=O)C(C)OC</smiles><smiles>C=C(NCC)C(C)OC</smiles><smiles>CNC(=Cc1ccccc1)C(C)(C)C</smiles>

For the complexes of the binol-derived $\mathbf{L}_{\mathbf{a}-\mathbf{d}}$ with DMI and MAA, the highest ee was obtained with the $\mathrm{PCy}_{2}$ derivative: $\mathbf{L}_{\mathbf{a}}<\mathbf{L}_{\mathbf{b}}<\mathbf{L}_{\mathbf{c}}>\mathbf{L}_{\mathbf{d}}$ (entries 1-12 in Table 1). For the complexes of the 3,3'-substituted ligands $\mathbf{L}_{\mathbf{d}-\mathbf{f}}$, the highest ee was obtained when the 3,3'-substituents were Ph: $\mathbf{L}_{\mathbf{d}}<\mathbf{L}_{\mathbf{e}}>\mathbf{L}_{\mathbf{f}}$ (entries 10-18 in Table 1). With complexes of the phospholane-derived ligand $\mathbf{L}_{\mathbf{g}-\mathbf{j}}$, the enantioselectivity was greatest for the $\mathrm{P}^{t} \mathrm{Bu}_{2}$ ligand: $\mathbf{L}_{\mathbf{g}}<\mathbf{L}_{\mathbf{h}}<\mathbf{L}_{\mathbf{i}}<\mathbf{L}_{\mathbf{j}}$ (entries 19-30). It is apparent from Fig. 2 that the performance of any particular ligand can be highly substrate-dependent.

The absolute configuration of the asymmetric hydrogenation products obtained with Rh-diphos complexes generally obey the quadrant-blocking rule; that is, blocked upper left quadrant leads to $R$-configuration for MAC and MAA and $S$-configuration for DMI. ${ }^{13}$ The nature of the quadrant blocking is best discerned
Table 1 Asymmetric hydrogenation catalysis ${ }^{a}$

\begin{tabular}{|c|c|c|c|c|c|}
\hline Entry & Ligand & DMI & MAA & MAC & Conv. (\%) \\
\hline 1 & $\mathbf{L}_{\mathbf{a}}$ & $68(S)$ & & & 100 \\
\hline 2 & $\mathbf{L}_{\mathbf{a}}$ & & $46(R)$ & & 100 \\
\hline 3 & $\mathbf{L}_{\mathbf{a}}$ & & & $35(R)$ & 100 \\
\hline 4 & $\mathbf{L}_{\mathbf{b}}$ & $90(S)$ & & & 100 \\
\hline 5 & $\mathbf{L}_{\mathbf{b}}$ & & $72(R)$ & & 100 \\
\hline 6 & $\mathbf{L}_{\mathbf{b}}$ & & & $56(R)$ & 100 \\
\hline 7 & $\mathbf{L}_{c}$ & $95(S)$ & & & 100 \\
\hline 8 & $\mathbf{L}_{c}$ & & $76(R)$ & & 100 \\
\hline 9 & $\mathbf{L}_{\mathbf{c}}$ & & & $61(R)$ & 100 \\
\hline 10 & $\mathbf{L}_{\mathbf{d}}$ & $91(S)$ & & & 100 \\
\hline 11 & $\mathbf{L}_{\mathbf{d}}$ & & $65(R)$ & & 100 \\
\hline 12 & $\mathbf{L}_{\mathbf{d}}$ & & & $64(R)$ & 100 \\
\hline 13 & $\mathbf{L}_{\mathbf{e}}$ & $94(S)$ & & & 56 \\
\hline 14 & $\mathbf{L}_{\mathbf{e}}$ & & $98(R)$ & & 100 \\
\hline 15 & $\mathbf{L}_{\mathbf{e}}$ & & & $94(R)$ & 49 \\
\hline 16 & $\mathbf{L}_{\mathbf{f}}$ & $91(S)$ & & & 47 \\
\hline 17 & $\mathbf{L}_{\mathbf{f}}$ & & $72(R)$ & & 35 \\
\hline 18 & $\mathbf{L}_{\mathbf{f}}$ & & & $93(R)$ & 20 \\
\hline 19 & $\mathbf{L}_{\mathrm{g}}$ & $62(R)$ & & & 100 \\
\hline 20 & $\mathbf{L}_{g}$ & & $57(S)$ & & 100 \\
\hline 21 & $\mathbf{L}_{g}$ & & & $46(S)$ & 99 \\
\hline 22 & $\mathbf{L}_{\mathbf{h}}^{\circ}$ & $97(R)$ & & & 100 \\
\hline 23 & $\mathbf{L}_{\mathbf{h}}$ & & $90(S)$ & & 100 \\
\hline 24 & $\mathbf{L}_{\mathbf{h}}$ & & & $85(S)$ & 39 \\
\hline 25 & $\mathbf{L}_{\mathbf{i}}$ & $92(R)$ & & & 100 \\
\hline 26 & $\mathbf{L}_{\mathbf{i}}$ & & $96(S)$ & & 100 \\
\hline 27 & $\mathbf{L}_{\mathbf{i}}$ & & & $85(S)$ & 22 \\
\hline 28 & $\mathbf{L}_{\mathbf{j}}$ & $99(R)$ & & & 100 \\
\hline 29 & $\mathbf{L}_{\mathbf{j}}$ & & $98(S)$ & & 100 \\
\hline 30 & $\mathbf{L}_{\mathbf{j}}$ & & & $99(S)$ & 26 \\
\hline
\end{tabular}

${ }^{a}$ Reaction conditions: S/C $=100: 1,5$ bar $\mathrm{H}_{2}, 20{ }^{\circ} \mathrm{C}, 1 \mathrm{~h}, \mathrm{CH}_{2} \mathrm{Cl}_{2}$. Enantioselectivities were determined by chiral GC analysis (see ESI for details).

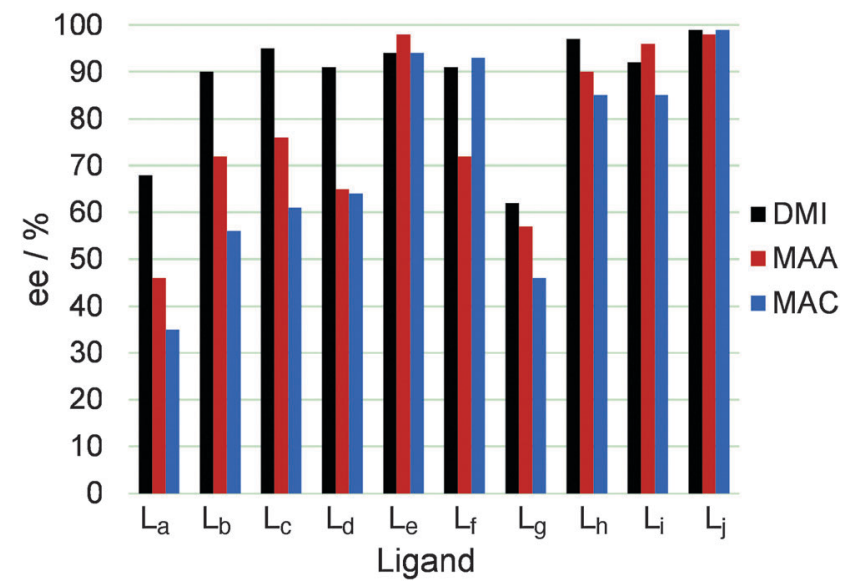

Fig. 2 Graph of the enantioselectivities obtained with each of the catalysts.

from crystal structures and so crystals of the $\left[\mathrm{Rh}(\operatorname{cod})\left(\mathbf{L}_{\mathbf{j}}\right)\right] \mathrm{BF}_{4}(\mathbf{3} \mathbf{j})$ were grown and its crystal structure determined, which has two molecules in the asymmetric unit (Fig. 3). Attempts to grow crystals suitable for X-ray crystallography of Rh-complexes of the binol-derived ligands $\left(\mathbf{L}_{\mathbf{a}-\mathbf{d}}\right)$ have so far been unsuccessful, although crystals of the chelate $\left[\operatorname{PtCl}_{2}\left(\mathbf{L}_{\mathbf{d}}\right)\right](\mathbf{4 d})$ have been obtained and its structure is shown in Fig. 4. In both structures (3j and $\mathbf{4 d}$ ), the acute $\mathrm{P}-\mathrm{M}-\mathrm{P}$ angles of $72.84(3)^{\circ}$ in $3 \mathbf{j}$ and $73.74(3)^{\circ}$ in $4 \mathbf{d}$ indicate the degree of strain present in the 4-membered chelates; these values are very similar to the $72.55(6)^{\circ}$ that was 


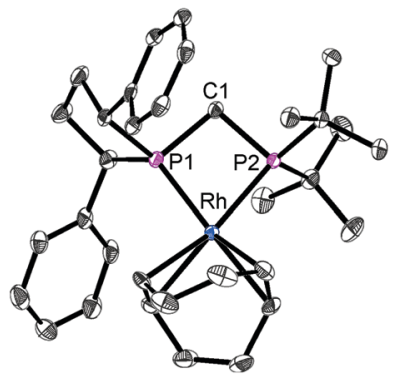

(a)

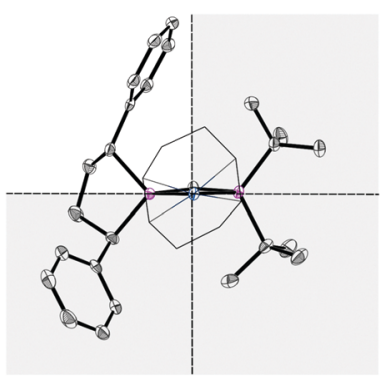

(b)
Fig. 3 (a) Crystal structure of $\mathbf{3 j}$. Thermal ellipsoids are plotted at $50 \%$ probability. Hydrogen atoms and the $\mathrm{BF}_{4}$ counterion have been omitted for clarity. The two molecules in the asymmetric unit have the same orientation hence only one is shown for clarity. Selected bond lengths $(\AA)$ and angles $\left({ }^{\circ}\right)$ : Rh1-P1 2.2839(7), Rh1-P2 2.3198(7), P1-C1 1.841(3), P2-C1 1.846(3), P1-Rh1-P2 72.84(3), P1-C1-P2 95.68(13). (b) Quandrant diagram of 3j, where shaded area represents a blocked quadrant.

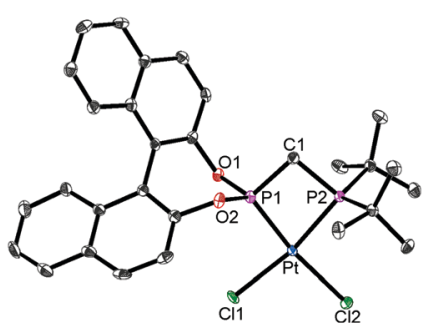

(a)

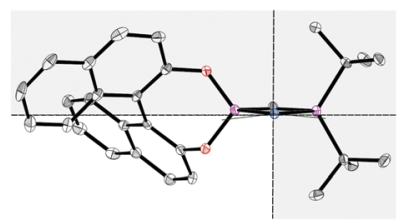

(b)
Fig. 4 (a) Crystal structure of $\mathbf{4 d}$. Thermal ellipsoids are plotted at 50\% probability. Hydrogen atoms have been omitted for clarity. Selected bond lengths ( $\AA$ ) and angles ( ${ }^{\circ}$ ): Pt-Cl1 2.3572(8), Pt-Cl2 2.3657(8), Pt-P1 2.1620(9), Pt-P2 2.2596(8), P1-C1 1.798(3), P2-C11.866(3), P1-Pt-P2 73.74(3), P1-C1-P2 92.83(15), O1-P1-O2 104.26(13). (b) Quandrant diagram of 4d, where shaded area represents a blocked quadrant.

determined in an analogous complex of Trichickenfootphos (F in Fig. 1). ${ }^{8}$ The mean planes through $\mathrm{M}-\mathrm{P}-\mathrm{P}-\mathrm{C}$ have rms deviations of $0.035 / 0.049 \AA$ in $3 \mathbf{j}$ and $0.003 \AA$ in $\mathbf{4 d}$ showing that the chelates are almost planar (see Fig. 3 and 4). It is evident from Fig. 4 that the upper left quadrant is blocked in the $\mathbf{L}_{\mathbf{d}}$ complex (and presumably the same would be the case for all the ligands $\mathbf{L}_{\mathbf{a}-\mathbf{f}}$ ) while Fig. 3 shows lower left quadrant is blocked in the in $\mathbf{L}_{\mathbf{j}}$ complex (and presumably the same would be the case for all the ligands $\mathbf{L}_{\mathbf{g}_{-j}}$ ). Therefore, the absolute configurations of the products of asymmetric hydrogenation (Table 1) conform to the quadrant rule.

The remarkable efficiency of the ligand synthesis (Scheme 1) coupled with the ready removal of the volatile chlorosilane by-product suggested that a one-pot procedure may be feasible. This was carried out according to Scheme 2 for $\mathbf{L}_{\mathbf{j}}$ and the product tested for asymmetric hydrogenation of MAA. The $97 \%$ ee that was obtained compares favourably with the $98 \%$ ee recorded with the isolated complex (Table 1).

The simplicity and generality of the chlorosilane elimination route shown in Scheme 1 to $C_{1}$-symmetric, $\mathrm{C}_{1}$-backboned, optically pure diphos ligands has been demonstrated by varying the nature of the two P-reagents. The success of the one-pot procedure (Scheme 2), coupled with the fact that the number of

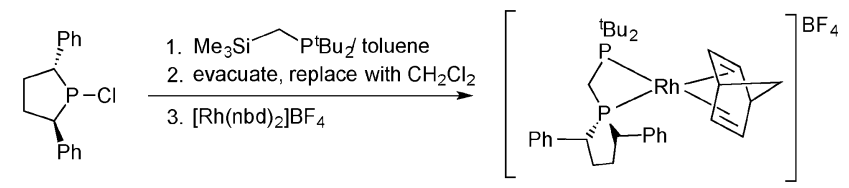

Scheme 2 One pot synthesis of $\left[R h(n b d)\left(L_{j}\right)\right]$.

potential ligands increases geometrically with each new chlorophos or silylmethylphosphine component, opens up the possibility of applying HTE methods to diphosphine synthesis and catalyst screening in a way that previously, have only been applied to monophos ligands. This is currently under investigation as is the mechanism of the ligand formation reaction.

We thank EPSRC for supporting this work with a studentships to ELH.

\section{Notes and references}

1 W. S. Knowles and M. J. Sabacky, Chem. Commun., 1968, 1445-1446.

2 L. Horner, H. Siegel and H. Büthe, Angew. Chem., Int. Ed. Engl., 1968, 7, 942.

3 T. P. Dang and H. B. Kagan, J. Chem. Soc. D, 1971, 481.

4 W. S. Knowles, M. J. Sabacky, B. D. Vineyard and D. J. Weinkauff, J. Am. Chem. Soc., 1975, 97, 2567-2568.

5 A. Miyashita, A. Yasuda, H. Takaya, K. Toriumi, T. Ito, T. Souchi and R. Noyori, J. Am. Chem. Soc., 1980, 102, 7932-7934.

6 M. J. Burk, J. Am. Chem. Soc., 1991, 113, 8518-8519.

7 Y. Yamanoi and T. Imamoto, J. Org. Chem., 1999, 64, 2988-2989.

8 G. Hoge, H.-P. Wu, W. S. Kissel, D. A. Pflum, D. J. Greene and J. Bao, J. Am. Chem. Soc., 2004, 126, 5966-5967.

9 M. van den Berg, A. J. Minnaard, E. P. Schudde, J. van Esch, A. H. M. de Vries, J. G. de Vries and B. L. Feringa, J. Am. Chem. Soc., 2000, 122, 11539-11540.

10 J. G. de Vries and C. J. Elsevier, The Handbook of Homogeneous Hydrogenation, Wiley-VCH, 2008.

11 C. Jäkel and R. Paciello, US Patent, 2008/269528, 2008.

12 (a) J. A. Gillespie, D. L. Dodds and P. C. J. Kamer, Dalton Trans., 2010, 39, 2751-2764; (b) G. M. Noonan, J. A. Fuentes, C. J. Cobley and M. L. Clarke, Angew. Chem., Int. Ed., 2012, 51, 2477-2480; (c) X. Wang, F. Meng, Y. Wang, Z. Han, Y.-J. Chen, L. Liu, Z. Wang and K. Ding, Angew. Chem., Int. Ed., 2012, 51, 9276-9282; (d) T. Imamoto, K. Tamura, Z. Zhang, Y. Horiuchi, M. Sugiya, K. Yoshida, A. Yanagisawa and I. D. Gridnev, J. Am. Chem. Soc., 2012, 134, 1754-1769; (e) S. H. Chikkali, R. Bellini, B. de Bruin, J. I. van der Vlugt and J. N. H. Reek, J. Am. Chem. Soc., 2012, 134, 6607-6616; $(f)$ N. Khiri-Meribout, E. Bertrand, J. Bayardon, M.-J. Eymin, Y. Rousselin, H. Cattey, D. Fortin, P. D. Harvey and S. Jugé, Organometallics, 2013, 32, 2827-2839; $(g)$ A. Zirakzadeh, M. A. Groß, Y. Wang, K. Mereiter, F. Spindler and W. Weissensteiner, Organometallics, 2013, 32, 1075-1084; $(h)$ W. Chen, F. Spindler, B. Pugin and U. Nettekoven, Angew. Chem., Int. Ed., 2013, 52, 8652-8656; (i) A. Zirakzadeh, M. A. Groß, Y. Wang, K. Mereiter and W. Weissensteiner, Organometallics, 2014, 33, 1945-1952; ( $j$ ) G. Shang, W. Li and X. Zhang, Catalytic Asymmetric Synthesis, John Wiley \& Sons, Inc., 2010, pp. 343-436.

13 I. D. Gridnev and T. Imamoto, Acc. Chem. Res., 2004, 37, 633-644.

14 I. D. Gridnev, T. Imamoto, G. Hoge, M. Kouchi and H. Takahashi, J. Am. Chem. Soc., 2008, 130, 2560-2572.

15 (a) A. H. Hoveyda, A. W. Bird and M. A. Kacprzynski, Chem. Commun., 2004, 1779-1785; (b) J. G. de Vries and L. Lefort, Chem. - Eur. J., 2006, 12, 4722-4734; (c) W. Zhang, Y. Chi and X. Zhang, Acc. Chem. Res., 2007, 40, 1278-1290.

16 R. den Heeten, B. H. G. Swennenhuis, P. W. N. M. van Leeuwen, J. G. de Vries and P. C. J. Kamer, Angew. Chem., Int. Ed., 2008, 47, 6602-6605.

17 (a) L. Lefort, J. A. F. Boogers, A. H. M. de Vries and J. G. de Vries, Org. Lett., 2004, 6, 1733-1735; (b) L. Lefort, J. A. F. Boogers, A. H. M. de Vries and J. G. de Vries, Top. Catal., 2006, 40, 185-191.

18 (a) R. Appel, K. Geisler and H. F. Scholer, Chem. Ber./Recl., 1979, 112, 648-653; (b) J. Wolf, M. Manger, U. Schmidt, G. Fries, D. Barth, 
B. Weberndorfer, D. A. Vicic, W. D. Jones and H. Werner, J. Chem. Soc., Dalton Trans., 1999, 1867-1875; (c) R. L. Keiter, D. Chen, G. A. Holloway, E. A. Keiter, Y. Zang, M. T. Huml, J. Filley and D. E. Brandt, Organometallics, 2012, 31, 4619-4622.

19 J. Campora, C. M. Maya, I. Matas, B. Claasen, P. Palma and E. Alvarez, Inorg. Chim. Acta, 2006, 359, 3191-3196.
20 A. S. Ionkin, Y. Wang, W. J. Marshall and V. A. Petrov, J. Organomet. Chem., 2007, 692, 4809-4827.

21 M. J. Baker and P. G. Pringle, J. Chem. Soc., Chem. Commun., 1991, 1292-1293.

22 P. Haranath, U. Anasuyamma, C. Devendranath Reddy and C. Suresh Reddy, Heterocycl. Commun., 2005, 11, 335-342. 